\title{
Design of UPFC controllers and supplementary damping controller for power transmission control and stability enhancement of a longitudinal power system
}

\author{
C.-T. Chang and Y.-Y. Hsu
}

\begin{abstract}
The application of unified power flow controllers (UPFCs) to redistribute the power flows over two disproportionate parallel corridors and to boost the low-voltage profile on the transmission networks of the Taiwan power system is examined. A detailed dynamic generator model is used for a UPFC controller design to give more accurate controller parameters. A power system supervisor and conditioner (PSSC) is proposed to determine proper reference busbar voltages and series power flows for the UPFC control system. To improve system dynamic performance under disturbance conditions, a systematic approach based on the root locus method and pole assignment is developed to reach proper proportional-integral (PI) controller gains for the UPFC control system. In addition, a supplementary damping controller is designed to improve the damping for low-frequency electromechanical mode oscillations. To demonstrate the effectiveness of the proposed UPFC control system, computer simulations are performed to reach the steadystate and dynamic responses of the Taiwan power system. It is concluded from the simulation results that not only the requirements on steady-state power transfer and voltage profile can be obtained, but also the satisfactory system dynamic responses can be achieved by co-ordinated application of the designed UPFC control system.
\end{abstract}

List of symbols

General

$v$
$i$
$L$
$R$
$e$
$C$
$P$
$Q$
$\theta$

$\omega$

$\alpha$

$K$

$\mathbf{X}$

$\mathbf{Y}$

$m$

$\delta$

Subscripts $a, b, c$ busbar voltage current inductance resistance inverter output voltage capacitance real power reactive power angle between synchronous rotating reference axis and selected reference axis angular speed angle by which the Statcom output voltage leads the compensated busbar voltage

controller gain

state vector

output vector

modulation index

inverter phase angle

quantities in phases $a, b$, and $c$ for the shunt inverter

(1) IEE, 2002

IEE Proccedings online no. 20020199

DOI: $10.1049 /$ ip-gtd:20020199

Paper first received 27th September 2001 and in revised form 14th January 2002

The authors are with the National Taiwan University, Room 244, EE Building

II. Roosevelt Road Section 4, Taipei 106. Taiwan, Republic of China

$\begin{array}{ll}d, q & \text { quantities in } d \text {-axis and } q \text {-axis for the } \\ d c & \text { shunt inverter } \\ \text { filter } & \text { DC link } \\ P & \text { filtering inductor } \\ r & \text { parallel connection } \\ s & \text { receiving end } \\ \text { series } & \text { sending end } \\ \text { shunt } & \text { UPFC series inverter system } \\ \text { ser } & \text { UPFC shunt inverter system } \\ \text { sera, serb, serc } & \text { the compensated transmission line } \\ \text { serd, serq } & \text { series inverter } \\ t & \text { quantities in } d \text { and } q \text { axes for the series } \\ \text { inverter } & \text { transmission line } \\ & \text { quantities in } d \text { and } q \text { axes for the sending } \\ r d, r q & \text { end busbar } \\ t r & \text { quantities in } d \text { and } q \text { axes for the receiving } \\ \text { Superscript } & \text { end busbar } \\ * & \text { transformer }\end{array}$

\section{Introduction}

In the daily operation of the Taiwan power system, potential problems on low busbar voltages, line overloads, and low-frequency oscillation have been of great concern to system operators, as a result of heavy power flows over the $345 \mathrm{kV}$ transmission lines connecting the northern area and the central and southern areas $[1,2]$. 
Unified power flow controllers (UPFCs) have been proposed in recent years [3-11] to integrate the busbar voltage regulation capability of static synchronous compensators (Statcoms) and power flow control capability of static series compensators (SSSCs) in a single compensation device. The basic principles on how busbar voltage regulation and reactive power compensation and power flow control can be achieved by a UPFC have been described in [3-6]. The performance and operating experience for a UPFC comprising two \pm 160 MVA VSIs were reported in [7]. Nabavi-Niaki and Iravani [8] developed the steady state and dynamic models for the UPFC. Based on the decoupling technique of direct and quadrature axes current components presented in [12], Papic et al. [9] and Padiyar and Kulkarni [10] examined the design of a UPFC controller

The main purpose of this paper is to examine the feasibility of potential use of a UPFC to alleviate the transmission bottleneck between the northern area and the central and southern areas of the Taiwan power system, as mentioned earlier. The UPFC is expected to alleviate line overloads by controlling the power flows over the $345 \mathrm{kV}$ transmission lines and to regulate busbar voltages through reactive power compensation. The main features of this work are summarised as follows:

(a) In contrast to most work on UPFC controller design [8-10] in which a constant voltage in series with an impedance is used for source model, a detailed dynamic generator model is used in this paper. It is expected that the more rigorous source model will give more accurate controller parameters for the UPFC and, therefore, yield better dynamic performance for the system, especially from the viewpoint of supplementary damping controller design.

(b) A power system supervisor and conditioner is proposed for the determination of proper reference powers $P_{\text {ser }}^{*}$ and $Q_{\text {ser }}^{*}$ and busbar reference voltage $\left|v_{s}\right|^{*}$ for the UPFC control system.

(c) A systematic approach based on root locus method and pole assignment is developed to reach proper proportional-integral (PI) controller gains for the power flow regulator, shunt current regulator, DC busbar voltage regulator, and $\mathrm{AC}$ busbar voltage regulator, respectively. In addition, a supplementary damping controller is designed to improve the damping for low-frequency electromechanical mode oscillations.

\section{The UPFC system}

As shown in Fig. 1, the Taiwan power system is a typical longitudinal power system where major load centres are located in the north, while most generating plants are in centre and south $[1,2]$. In view of the potential line overload problem, as a result of the disproportionate power flows between the two corridors, and the low busbar voltage problem at busbar 5 due to insufficient reactive power sources nearby [2], a UPFC is proposed to be installed at busbar 5 (OMEI), as shown in Fig. 1.

For the design of a UPFC, the northern area in Fig. 1 is represented as an infinite busbar while the central and southern areas are represented as an equivalent generator. Note that a complete nonlinear generator model described by a set of seven nonlinear differential equations is used in this study. Details for the seven differential equations can be found in [13]. In addition, the IEEE type ST2A excitation system [14], which can be described by a set of four differential equations and a saturation function, is employed

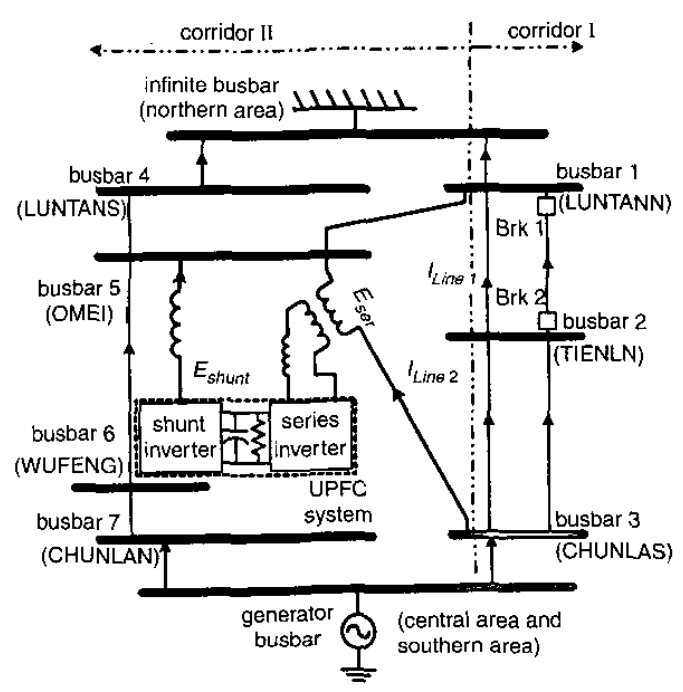

Fig. 1 One-line diagram of the $345 \mathrm{kV}$ transmission system connecting the northern area and central area of Taiwan

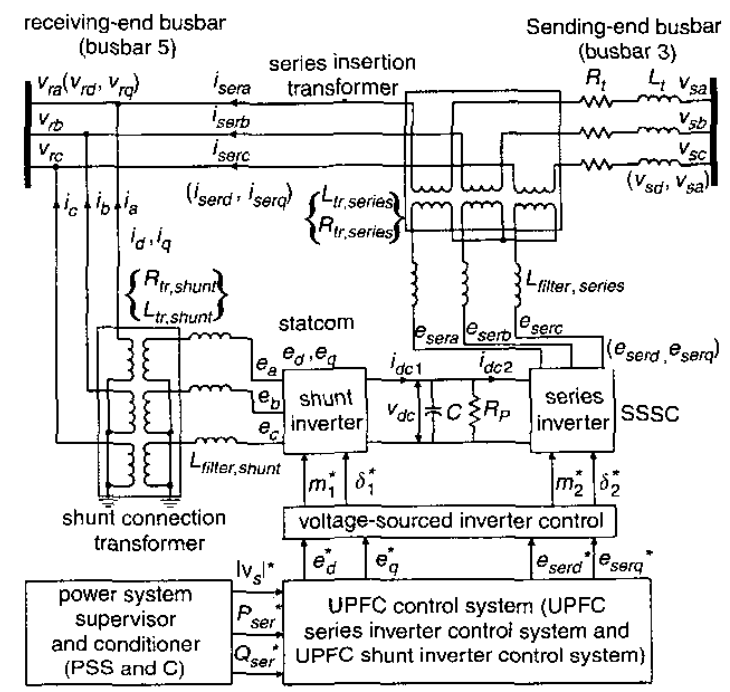

Fig. 2 Basic structure and control blocks of a UPFC system

in this work. The parameters for the generator and excitation system can be found in [15].

As shown in Fig. 2, the power flow control is achieved by injecting series controllable voltages $e_{\text {sera }}, e_{\text {serb }}$, and $e_{\text {serc }}$ through the series insertion transformer, while busbar voltage regulation is accomplished by injecting shunt compensating currents $i_{c}, i_{b}$ and $i_{c}$ into the busbar to be compensated. SSSC and STATCOM voltages are generated by the series inverter and shunt inverter, respectively, Note that these two inverters are operated from a common DC link provided by a DC capacitor and are assumed to provide balanced three-phase sinusoidal voltages at fundamental frequency. To control line flows and regulate busbar voltages, these inverter voltages are normally controlled by varying the modulation index $m$ and phase angle $\delta$.

The modulation indices $m$ and phase angles $\delta$ for the two inverters are determined by the UPFC control system described in Section 4 based on the described busbar voltage $\left|v_{s}\right|^{*}$, and desired line flows $P_{s e r}^{*}$ and $Q_{\text {ser }}^{*}$, which in turn, are determined by the power system supervisor and conditioner to be described in the following Section. 


\section{Steady-state performance of the power system with the UPFC}

\subsection{Power system supervisor and conditioner}

As shown in Fig. 2, a power system supervisor and conditioner (PSSC) block is included in the UPFC to reach the desired busbar voltage $\left|v_{s}\right|^{*}$ and the desired line flows $P_{s e r}^{*}$ and $Q_{s e r}^{*}$ for the UPFC control system. Fig. 3 shows the iterative procedure followed by the PSSC to reach $\left|v_{s}\right|^{*}$, $P_{s e r}^{*}$ and $Q_{s e r}^{*}$. Details for the iterative procedure are described as follows:

Step 1: Perform power flow analysis for the power system without UPFC.

Step 2: As the voltage for busbar 5 in Fig. 1 is below the allowable lower limit, try to improve the voltage at this busbar by the UPFC. The Taiwan Power Company (TPC) requires that busbar voltages must be higher than 0.97 p.u. at the normal situation. This lower limit is chosen as the initial value for $\left|v_{s}\right|^{*}$. Once $\left|v_{s}\right|^{*}$ is determined, the required shunt inverter output voltage $\left(e_{q,}, e_{b}\right.$ and $e_{c}$ or $e_{d}$ and $\left.e_{q}\right)$ can be computed. As inverter output voltage is limited by the modulation index $m$ and capacitor voltage $v_{d c}$, it is essential that the inverter output voltage does not exceed its upper limit in the process of improving $\left|v_{s}\right|^{*}$.

Step 3: The reference powers for the line with the UPFC, $P_{s e r}^{*}$ and $Q_{s e r}^{*}$ are determined based on the criterion that the compensated line and other parallel lines are loaded to nearly the same percentages of their thermal limits. The reference powers $P_{s e r}^{*}$ and $Q_{s e r}^{*}$ are updated until no further refinements are necessary or until the upper limit for series inverter output voltage $\left(e_{\text {sera }}, e_{\text {serb }}\right.$ and $e_{\text {sere }}$, or $e_{\text {serd }}$ and $\left.e_{\text {serq }}\right)$ is reached.

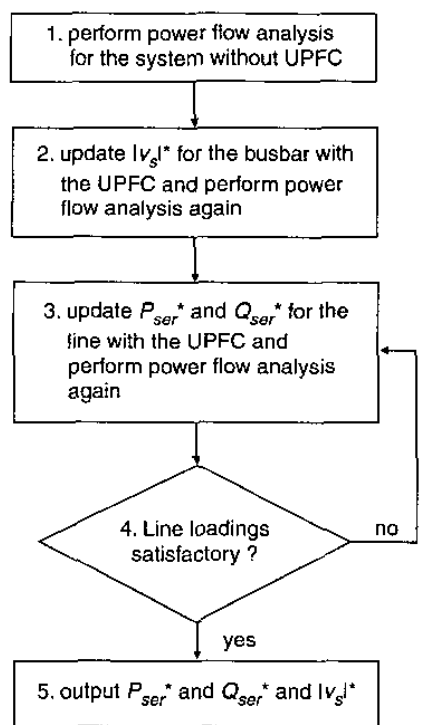

Fig. 3. Iterative procedures for the PSSC to determine $\left|v_{s}\right|^{*}, P_{s e}^{*}$ and $Q_{\text {ser }}^{*}$

\subsection{Steady-state performance for the compensated system}

When the UPFC with the proposed PSSC is installed at busbar 5, the line flows and busbar voltage for the compensated system are described in Table $1 b$. For the system with all lines in service, the busbar voltage at busbar 5 is improved from 0.9586 p.u. to 0.98 p.u.

As for the line flows over the two corridors, potential risk of line overload on corridor I is relieved because part of the line flows over this corridor is shifted to the lines on corridor II and as SSSC is installed at the line between busbar 5 and busbar 3 on corridor II. It is noted that line 1-2 on corridor $I$ and line $5-3$ are loaded to the same percentage $(77 \%)$ of their thermal ratings.

Also listed in Table $1 b$ are the line flows and busbar voltage for the outage case with one of two lines between busbar 1 and busbar 2 tripped. Note that the PSSC does not respond immediately to update $\left|v_{s}\right|^{*}, P_{s e r}^{*}$ and $Q_{s e r}^{*}$ following an outage event until the possibility of a temporary fault is excluded. It is observed from Table $1 b$ that, under the situation of a permanent fault on a line between busbar 1 and busbar 2 , it is impossible to avoid line overloading completely. However, line overload on the remaining circuit between busbar 1 and busbar 2 is relieved to a great extent $(134 \%$ to $102 \%)$.

\section{The UPFC control system}

The state-space equations of the UPFC AC side circuits are given in [12]. The UPFC control system can be divided into two major subsystems, the UPFC series inverter control system as shown in Fig. 4 and the UPFC shunt inverter control system in Fig. 5. The primary function of the UPFC series inverter control system is to devise proper control signals $e_{\text {serd }}^{*}$ and $e_{\text {serq }}^{*}$, which can be used to compute the modulation index $m_{2}^{*}$ and the phase angle $\delta_{2}^{*}$ for the series inverter. On the other hand, the UPFC shunt inverter control system gives the control signals $e_{d}^{*}$ and $e_{q}^{*}$ and the modulation index $m_{1}^{*}$ and the phase angle $\delta_{1}^{*}$ for the shunt inverter. Details on the design of the proportional-integral controller gains for the power flow regulator $\left(K_{1}\right.$ and $\left.K_{2}\right)$, the shunt current regulator $\left(K_{3}\right.$ and $\left.K_{4}\right)$, the DC busbar voltage regulator $\left(K_{5}\right.$ and $\left.K_{6}\right)$ and the AC busbar voltage regulator $\left(K_{7}\right.$ and $\left.K_{8}\right)$ are described in the following Section.

Also shown in Fig. 4, a supplementary damping controller which is used to provide an additional damping signal in order to improve the damping for low-frequency electromechanical mode oscillations. A Pl controller with a wash-out function and a time-delay block is employed for the UPFC supplementary controller. In the present work, either the integral of the active power at the location of the SSSC, $\int P_{s e r} \mathrm{~d} t,[5]$ or generator angular speed deviation, $\Delta \omega,[6]$ is taken as the input of the damping controller. The output signal of the supplementary damping controller is added to the quadrature voltage reference $e_{\text {serq }}^{*}$ of the series injection voltage [5]. The wash-out time constant $T_{W}$ is chosen to be $3.0 \mathrm{~s}$ and the delay time constant $T_{D}$ is chosen to be $0.1 \mathrm{~s}$.

\section{Design of the UPFC controller}

In the design of the UPFC controller, the root locus method and pole-assignment approach will be used. The nonlinear equations of the study system including the generator, the UPFC dynamic model, the UPFC series inverter control system and the UPFC shunt inverter control system are linearised around a nominal operating point as follows:

$$
\begin{gathered}
\dot{\mathbf{X}}=\mathbf{A X}(t)+\mathbf{B u}(t) \\
\mathbf{Y}(t)=\mathbf{C X}(t)
\end{gathered}
$$

where $\mathbf{X}(t)$ the state vector comprising all state variables, $\mathbf{u}(t)$ is the input vector and $\mathbf{Y}(t)$ is the output vector. Table 2 summarises the models, control systems and the supplementary damping controller for six cases examined in this work, and Table 3 gives the eigenvalues for the six study cases. In case 1 , the authors consider the system without 
Table 1: Line flows

\begin{tabular}{|c|c|c|c|c|}
\hline \multicolumn{5}{|c|}{ a Line flows (MW/percentage of thermal limit) for the uncompensated system } \\
\hline \multirow{2}{*}{ Busbar number } & \multirow{2}{*}{$\begin{array}{l}\text { Case } \\
\text { busbar 1-2 }\end{array}$} & \multirow{2}{*}{$\begin{array}{l}\begin{array}{c}\text { Normal case (all } \\
\text { lines in service) }\end{array} \\
2093(91 \%)\end{array}$} & \multicolumn{2}{|c|}{$\begin{array}{l}\text { Outage case (one line between busbar } 1 \text { (LUNTSNN) and } \\
\text { busbar } 2 \text { (TIENLN) is tripped) }\end{array}$} \\
\hline & & & \multicolumn{2}{|l|}{$1587(138 \%)$} \\
\hline & busbar 2-3 & $2160(91 \%)$ & \multicolumn{2}{|l|}{$1638(69 \%)$} \\
\hline \multirow[t]{4}{*}{ Corridor II } & busbar 1-5 & $1180(58 \%)$ & \multicolumn{2}{|l|}{$1526(75 \%)$} \\
\hline & busbar 4-5 & $1592(77 \%)$ & \multicolumn{2}{|l|}{$1840(89 \%)$} \\
\hline & busbar 5-3 & $1247(59 \%)$ & \multicolumn{2}{|l|}{$1585(75 \%)$} \\
\hline & busbar $5-6$ & $1679(81 \%)$ & \multicolumn{2}{|l|}{$1927(93 \%)$} \\
\hline \multicolumn{2}{|c|}{ Voltage at OMEI (p.u.) } & 0.9586 & \multicolumn{2}{|l|}{0.9335} \\
\hline \multicolumn{5}{|c|}{$b$ Line flows (MW/percent of thermal limit) for the compensated system } \\
\hline \multirow[t]{2}{*}{ Busbar number } & \multirow[t]{2}{*}{ Case } & \multirow[t]{2}{*}{$\begin{array}{l}\text { Normal case (all } \\
\text { lines in service) }\end{array}$} & \multicolumn{2}{|c|}{$\begin{array}{l}\text { Outage case (one line between busbar } 1 \text { (LUNTSNN) and } \\
\text { busbar } 2 \text { (TIENLN) is tripped) }\end{array}$} \\
\hline & & & Without PSSC & With PSSC \\
\hline \multirow[t]{2}{*}{ Corridor 1} & busbar 1-2 & $1771(77 \%)$ & $1540(134 \%)$ & $1172(102 \%)$ \\
\hline & busbar 2-3 & $1827(77 \%)$ & $1590(67 \%)$ & $1234(52 \%)$ \\
\hline \multirow[t]{4}{*}{ Corridor II } & busbar $1-5$ & $1282(63 \%)$ & $1485(73 \%)$ & $1627(80 \%)$ \\
\hline & busbar 4-5 & $1633(79 \%)$ & $1798(87 \%)$ & $1840(89 \%)$ \\
\hline & busbar $5-3$ & $1628(77 \%)$ & $1627(77 \%)$ & $2135(102 \%)$ \\
\hline & busbar 5-6 & $1492(72 \%)$ & $1907(92 \%)$ & $1555(75 \%)$ \\
\hline \multicolumn{2}{|c|}{ Voltage at OMEI (p.u.) } & 0.9800 & 0.9597 & 0.9698 \\
\hline
\end{tabular}

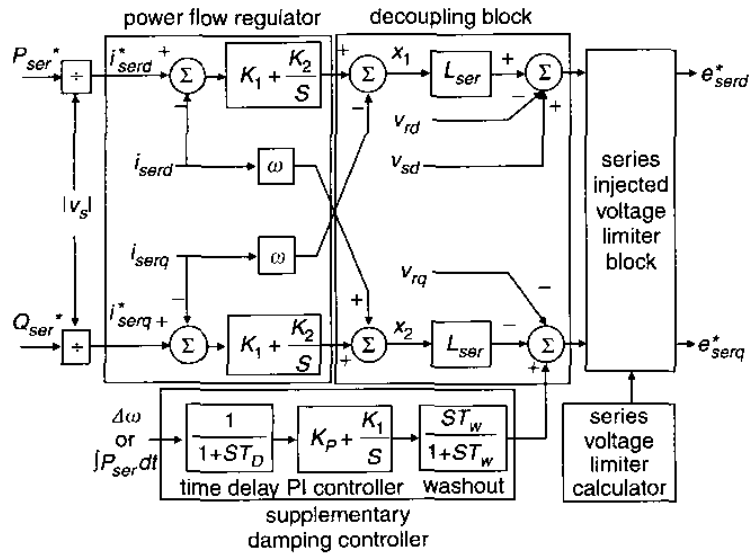

Fig. 4 Block diagram of the UPFC series inverter control system

UPFC and any control system. In case 2, the UPFC is included but the UPFC controllers are not considered. Note that the UPFC outputs $e_{\text {serel }}, e_{\text {serq }}, e_{d l}$ and $e_{q}$ remain constant in this case. It is observed from the eigenvalues in case 2 that, with the inclusion of the series inverter system and the shunt inverter system, a poorly damped series inverter mode characterised by the pair of eigenvalues $-14.6 \pm \mathrm{j} 377$ (with an oscillation frequency of $60 \mathrm{~Hz}$ ) and a poorly damped shunt inverter mode characterised by pair of eigenvalues $-19.42 \pm \mathrm{j} 377$ (with an oscillation frequency of $60 \mathrm{~Hz}$ ) are present. The electromechanical mode characterised by the pair of eigenvalues $-0.083 \pm \mathrm{j} 5.77$ (with an oscillation frequency of $0.92 \mathrm{~Hz}$ ) is also poorly damped. These modes should be shifted leftward to more desirable locations by the UPFC controllers and the UPFC supplementary damping controller.

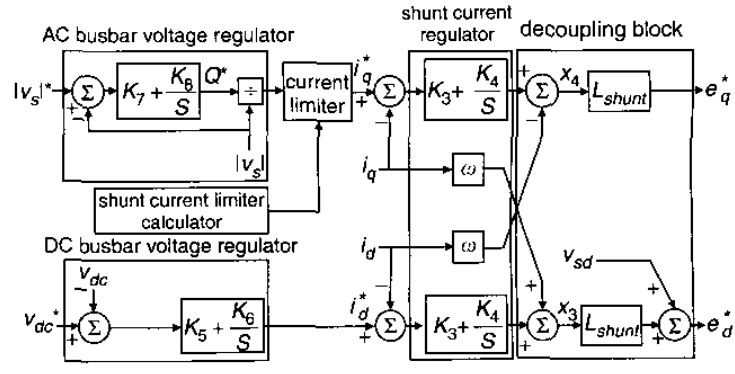

Fig. 5 Block diagram of the UPFC shunt inverter control system

\subsection{UPFC series inverter controller design}

Fig. $6 a$ shows the typical root loci for various combinations of parameters $K_{1}$ and $K_{2}$, and a proper pair of gains can be determined based on the consideration of enough phase margin, good damping and fast response. The pair of controller gains $K_{1}=4.0$ and $K_{2}=1.0$ has been determined for the power flow regulator after the eigenvalues for the series inverter mode $-14.6 \pm \mathrm{j} 377$ is shifted to the new locations $-254.5 \pm j 381.5$. The eigenvalues of the system with only series inverter model and control system are listed in case 3 of Table 3.

\subsection{UPFC shunt inverter controller design}

The authors will now proceed to decide the gains $K_{3}$ and $K_{4}$ for the shunt current regulator based on Fig. $6 b$ in the same manner. It is observed from Fig. $6 b$ that both good damping and fast response are achieved by the system with the controller gains $K_{3}=1.8$ and $K_{4}=1.5$. The eigenvalues for the shunt inverter mode are shifted to new locations $-258.3 \pm \mathrm{j} 268.4$, as shown in case 4 of Table 3 . The controller gains $K_{5}$ and $K_{6}$ for the DC busbar voltage regulator and $K_{7}$ and $K_{8}$ for the AC busbar voltage 
Table 2: Summary of models, control systems and supplementary damping controller for the six study cases

\begin{tabular}{|c|c|c|c|c|c|}
\hline \multirow[t]{2}{*}{ Case } & \multicolumn{2}{|c|}{ UPFC model } & \multicolumn{2}{|c|}{ Control system } & \multirow{2}{*}{$\begin{array}{l}\text { Supplementary } \\
\text { damping controller }\end{array}$} \\
\hline & $\begin{array}{l}\text { Series } \\
\text { inverter }\end{array}$ & $\begin{array}{l}\text { Shunt } \\
\text { inverter }\end{array}$ & $\begin{array}{l}\text { Series } \\
\text { inverter }\end{array}$ & $\begin{array}{l}\text { Shunt } \\
\text { inverter }\end{array}$ & \\
\hline \multicolumn{6}{|l|}{1} \\
\hline 2 & $*$ & * & & & \\
\hline 3 & $*$ & & * & & \\
\hline 4 & & * & & * & \\
\hline 5 & * & * & * & * & \\
\hline 6 & $*$ & * & $*$ & * & * \\
\hline
\end{tabular}

Table 3: Summary of system eigenvalues for the six study cases

\begin{tabular}{|c|c|c|c|c|}
\hline Case & $\begin{array}{l}\text { Generator and excitation } \\
\text { system }\end{array}$ & $\begin{array}{l}\text { Series inverter model } \\
\text { and system }\end{array}$ & $\begin{array}{l}\text { Shunt inverter model } \\
\text { and system }\end{array}$ & Transmission networks \\
\hline Case 1 & $\begin{array}{l}-3568 \pm j 145.4 \\
-0.0566 \pm j 4.9^{@} \\
-17.42,-16.4 \\
-1.02,-33.25 \\
-0.19,-1.391,-200\end{array}$ & & & $\begin{array}{l}-279 \pm j 449-6 \\
-364.7 \pm j 400 \\
-233.6 \pm j 417.7 \\
-33.44 \pm j 441.3 \\
-27.56 \pm j 377\end{array}$ \\
\hline Case 2 & $\begin{array}{l}-1918 \pm j 362.7 \\
-0.083 \pm j 5.77^{@} \\
-17.8 \pm j 1.02,-4 \pm j 6.52 \\
-1.02,-33.25,-200\end{array}$ & $-14.6 \pm j 377$ & $\begin{array}{l}-19.42 \pm j 377^{\#} \\
-0.0061\end{array}$ & $\begin{array}{l}-289.2 \pm 426 \\
-259 \pm 497.6 \\
-108.8 \pm 414.7 \\
-81.1 \pm 403.4\end{array}$ \\
\hline Case 3 & $\begin{array}{l}-1902 \pm j 362.7 \\
-0.092 \pm j 4.95^{@} \\
-17.8 \pm j 1.02,-4 \pm j 6.52 \\
-1.02,-33.25,-200\end{array}$ & $\begin{array}{l}-254 \pm j 381.5^{+} \\
-652.6 \pm j 719.8\end{array}$ & & $\begin{array}{l}-285 \pm j 40.4 \\
-232.4 \pm j 419.2 \\
-171.2 \pm j 369.8 \\
-94.2 \pm j 409.6\end{array}$ \\
\hline Case 4 & $\begin{array}{l}-1818 \pm j 351.4 \\
-0.084 \pm j 5.4^{@} \\
-17.8 \pm j 1.02,-4 \pm j 6.52 \\
-1.02,-33.25 \\
-200\end{array}$ & & $\begin{array}{l}-258.3 \pm j 268.4^{\#} \\
-95.2 \pm j 392.8 \\
-405.2 \pm j 386.8 \\
-152.3 \pm j 60.9 \\
-12.3\end{array}$ & $\begin{array}{l}-282.1 \pm j 433.6 \\
-266.7 \pm j 407.9 \\
-121.9 \pm j 397.5 \\
-94.2 \pm j 409.6\end{array}$ \\
\hline Case 5 & $\begin{array}{l}-1916 \pm j 365.5 \\
-0.098 \pm j 4.9^{@} \\
-17.8 \pm j 1.02,-4 \pm j 6.52 \\
-1.02,-33.25 \\
200\end{array}$ & $\begin{array}{l}-254.3 \pm j 381.5^{+} \\
-654.7 \pm j 722.7\end{array}$ & $\begin{array}{l}-258.3 \pm j 268.4^{\#} \\
-96.3 \pm j 395.8 \\
-405.3 \pm j 386.8 \\
-152.3 \pm j 60.9 \\
-12.8\end{array}$ & $\begin{array}{l}-284 \pm \mathrm{j} 408.9 \\
-229.7 \pm \mathrm{j} 414.3 \\
-197.9 \pm \mathrm{j} 377 \\
-103.7 \pm \mathrm{j} 449.6\end{array}$ \\
\hline Case 6 & $\begin{array}{l}-1915 \pm j 366.1 \\
-1.3 \pm j 4.9 @ \\
-17.72 \pm j 1.01,-4 \pm 6.52 \\
-1.02,-33.23,-200 \\
-2.032,-21.8 \pm j 49.4\end{array}$ & $\begin{array}{l}-249.5 \pm j 379.5^{+} \\
-653.6 \pm j 720.4\end{array}$ & $\begin{array}{l}-251.2 \pm \mathrm{j} 269.2^{\#} \\
-86.1 \pm \mathrm{j} 395.2 \\
-404.8 \pm \mathrm{j} 389.4 \\
-147.7 \pm \mathrm{j} 62.5 \\
-11.9\end{array}$ & $\begin{array}{l}-284 \pm \mathrm{j} 408.9 \\
-229.7 \pm \mathrm{j} 414.3 \\
-197.9 \pm \mathrm{j} 377 \\
-103.7 \pm \mathrm{j} 449.6\end{array}$ \\
\hline
\end{tabular}

$\oplus_{\text {the electromechanical mode }}$

the series inverter mode of UPFC

\# the shunt inverter mode of UPFC

regulator are determined with the same procedure. It is found that the pair of controller gains $K_{5}=1.2$ and $K_{6}=0.6$ for DC busbar voltage regulator and $K_{7}=8.5$ and $K_{8}=0.3$ for the $\mathrm{AC}$ busbar voltage regulator give satisfactory dynamic $\mathrm{DC}$ and $\mathrm{AC}$ voltage responses. The eigenvalues of the system with only shunt inverter model and control system are listed in case 4 of Table 3 .

The eigenvalues for the system with both series inverter system and shunt inverter system are given in case 5 of Table 3. 


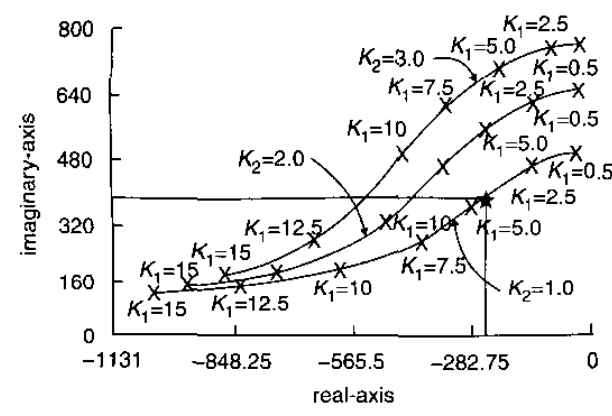

a

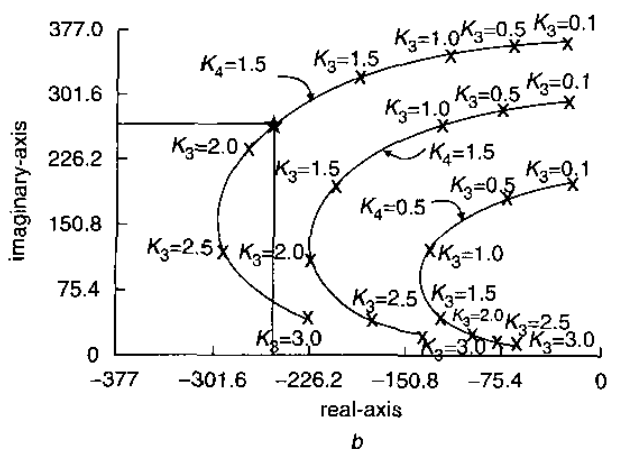

Fig. 6 Root loci for the design of power flow regulator ( $K_{1}$ and $\left.K_{2}\right)$ and shunt current regulator $\left(K_{3}\right.$ and $\left.K_{4}\right)$

a Root loci for various combinations of parameters $K_{1}$ and $K_{2}$

$b$ Root loci for various combinations of parameters $K_{3}$ and $K_{4}$

\subsection{UPFC supplementary damping controller design}

As far as the electromechanical mode is concerned, it is found that the pair of PI controller gains $K_{\mu}=17.4$ and $K_{I}=1.056$ for the UPFC supplementary damping controller will give satisfactory damping effect for the electromechanical mode by shifting the associated eigenvalues from $-0.098 \pm 4.9$ in case 5 to new locations $-1.3 \pm j 4.9$. The eigenvalues of the system with the UPFC control system and the proposed supplementary damping controller can be calculated and are listed in case 6 of Table 3. Note that the integral of line flow $\left(\int P_{\text {ser }} \mathrm{d} t\right)$ is used as the controller input.

\section{Dynamic performance simulation of the power system with the UPFC}

To demonstrate the effectiveness of the proposed UFC controller in improving the damping for the UPFC modes and the electromechanical modes, dynamic responses are investigated for the system in Fig. 1 subject to a three-phase fault on a line between busbar 1 and busbar 2. To examine the role that the power system supervisor and conditioner in Fig. 2 plays under contingency situations, dynamic responses following both a temporary fault event with a permanent fault event will be investigated.

\subsection{A temporary fault event}

The system is assumed to be at the steady-state operating conditions as described by the normal case in Table $1 a$ and $1 b$ before the fault event takes place. As shown in Table $1 a$ and $1 b$, the line current $I_{\text {Linel }}$ was $91 \%$ (system without UPFC) or $77 \%$ (system with UPFC) and $I_{\text {Line } 2}$ was $59 \%$ (system without UPFC) or $77 \%$ (system with UPFC) before the fault. As mentioned before, the heavy power flow

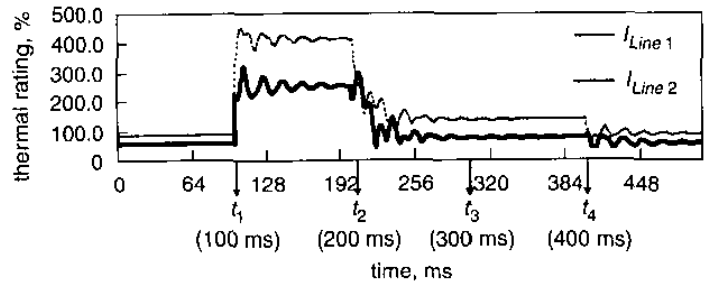

a

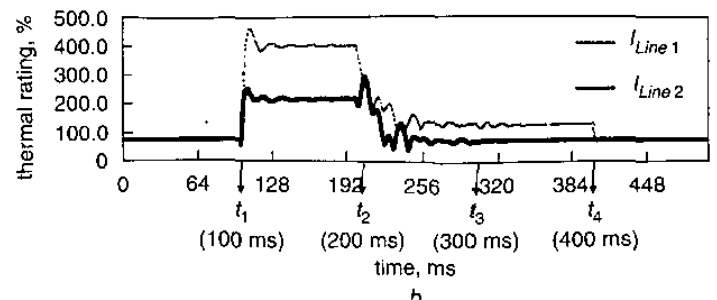

Fig. 7 Line current responses to a temporary fault $a$ Without UPFC compensation

$b$ With UPFC compensation

$t_{1}=100 \mathrm{~ms}$ fault initiated, SSSC bypassed

$t_{2}=200 \mathrm{~ms}$ breaker 1 and breaker 2 opened (faulted line tripped)

$t_{3}=300 \mathrm{~ms} \mathrm{SSSC}$ reinserted

$t_{4}=400 \mathrm{~ms}$ fautt cleared (breaker 1 and breaker 2 reclosed)

over corridor I has been reduced from $91 \%$ to $77 \%$ with the incorporation of a UPFC over corridor II.

To examine the dynamic responses of the system under disturbance conditions, a three-phase fault event as described in the following is assumed to take place on one of the two lines connecting busbar 1 and busbar 2 :

l. From $t=0$ to $t=t_{1}=100 \mathrm{~ms}$, the system is assumed to be at steady-state operating condition.

2. At $t=t_{1}=100 \mathrm{~ms}$, a three-phase fault is detected and the series portion of the UPFC, the SSSC, is bypassed through the action of the electronic bypass and mechanical bypass [6].

3. At $t=t_{2}=200 \mathrm{~ms}$, the faulted line is tripped by opening breaker 1 and breaker 2 .

4. At $t=t_{3}=300 \mathrm{~ms}$, the SSSC is reinserted.

5. At $t=t_{4}=400 \mathrm{~ms}$, the fault is cleared and breaker 1 and breaker 2 are reclosed.

On comparing the dynamic response curves in Figs. 7 and 8, the following observations can be made:

(a) As evidence by response curves in Fig. $7 a$ and $b$, better damping characteristic is achieved by the system with UPFC than that without UPFC. For the period from $t=100 \mathrm{~ms}$ to $t=200 \mathrm{~ms}$, the series inverter is bypassed and only the shunt inverter system is connected to the compensated busbar. Note that system damping is also improved by the UPFC even when only the shunt inverter system is present. This is also confirmed from the eigenvalues in Table $3(-33.44 \pm j 441.3$ and $-27.56 \pm j 377$ for case 1 and $-91.2 \pm j 408.2$ and $-39.8 \pm j 377$ for case 4 ).

(b) Before the faulted line is tripped at $\mathrm{t}=\mathrm{t}_{2}=200 \mathrm{~ms}$, the fault currents upto a level of $400 \%$ and $200 \%$ are observed for $I_{\text {Linel }}$ and $I_{\text {Line2 }}$, respectively, for both the case without UPFC and that with UPFC. UPFC is not capable of performing power flow transfer at all during this period. This is as expected since the SSSC has been bypassed.

(c) The SSSC is reinserted at the instant $t=t_{3}=300 \mathrm{~ms}$ when $I_{\text {Line2 }}$ reaches a post-contigency steady-state value. As the reference commands $\left|v_{s}\right|^{*}, P_{s e r}^{*}$ and $Q_{s e r}^{*}$ from the PSSC 


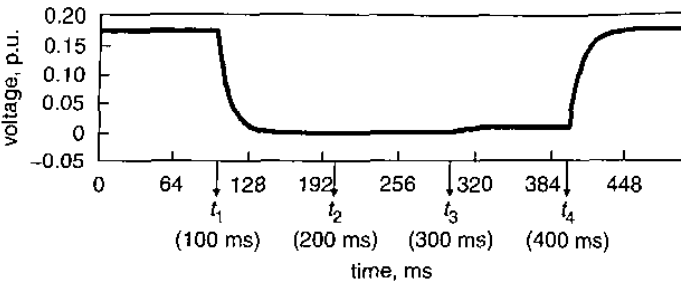

a

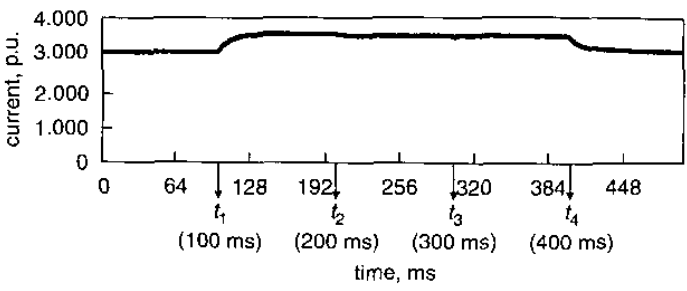

b

Fig. 8 System dynamic responses to a temporary fault with UPFC compensation

a Series injection voltage

$b$ Shunt injection current

$t_{1}=100 \mathrm{~ms}$ fault initiated, SSSC bypassed

$t_{2}=200 \mathrm{~ms}$ breaker 1 and breaker 2 opened (faulted line tripped) $t_{3}=300 \mathrm{~ms} \mathrm{SSSC}$ reinserted

$t_{4}=400 \mathrm{~ms}$ fault cleared (breaker 1 and breaker 2 reclosed)

remain unchanged in a temporary fault event, the UPFC will keep that line current $I_{\text {Linc } 2}$ at the same level $(77 \%)$ as the prefault steady-state value. As a result, a severe overload of $134 \%$ will be observed for $I_{\text {Linel }}$. UPFC seems to be unable to balance the power flows over the two corridors during this short period ( $t_{3}=300 \mathrm{~ms}<t<t_{4}=400 \mathrm{~ms}$ ).

(d) When breaker 1 and breaker 2 are reclosed and the faulted line is back to service again at $t=t_{4}=400 \mathrm{~ms}$, the line currents $I_{\text {Linel }}$ and $I_{\text {Line }}$ return to their prefault steadystate values, because the reference commands $\left|v_{s}\right|^{*}, P_{s i r}^{*}$, and $Q_{s e r}^{*}$ remain unchanged. By comparing the response curves during the period of $t>t_{4}=400 \mathrm{~ms}$ for the systcm without UPFC and for the system with UPFC, it is observed that better damping characteristics can be achieved by the system with UPFC than that without UPFC. This is as expected because the eigenvalues $-14.63 \pm \mathrm{j} 377$ and $-19.42 \pm \mathrm{j} 377$ in case 1 of Table 3 have been shifted by the UPFC control system to new locations $-254.5 \pm 381.5$ and $-258.3 \pm \mathrm{j} 268.4$ in case 5 of Table 3.

\subsection{A permanent fault}

The power system supervisor and conditioner did not work in the case of a temporary fault as described before. To sce how PSSC works in an outage event, the dynamic responses of the system subject to a permanent fault are simulated. The fault event is similar to that described in Section 6.1, expect that the fault is not cleared at $t=t_{4}$ and the faulted line remains open. In the present case, the percentage line currents over corridor I and corridor II are rather unbalanced $\left(138 \%\right.$ for $I_{\text {Linel }}$ and $75 \%$ for $\left.I_{\mathrm{Line} 2}\right)$ after the fault $\left(t>t_{3}\right)$ if the PSSC does not work and the reference setting $P_{s e r}^{*}$ and $Q_{s e r}^{*}$ remain unchanged (Fig. $9 a$ ). To balance the loadings between the two corridors, the reference settings $P_{s e r}^{*}$ and $Q_{s e r}^{*}$ are updated from $P_{s c r}^{*}=17.74$ p.u. $Q_{\text {ser }}^{*}=3.6$ p.u. to new values $P_{s e r}^{*}=21.64$ p.u. and $Q_{s e r}^{*}=4.1$ p.u. With the new reference setting $P_{s e r}^{*}$ and $Q_{s e r}^{*}$ it is observed from Fig. $10 a$ that the line currents are more balanced (102\% for $I_{\text {Linel }}$ and $102 \%$ for

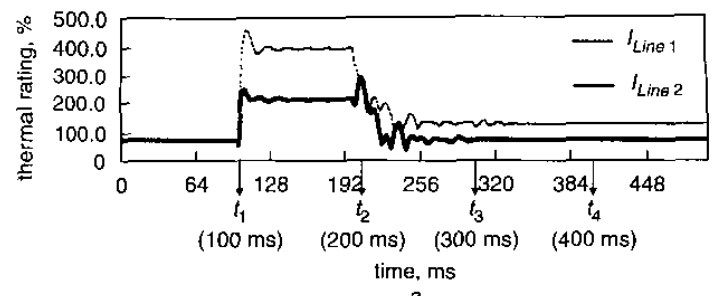

a

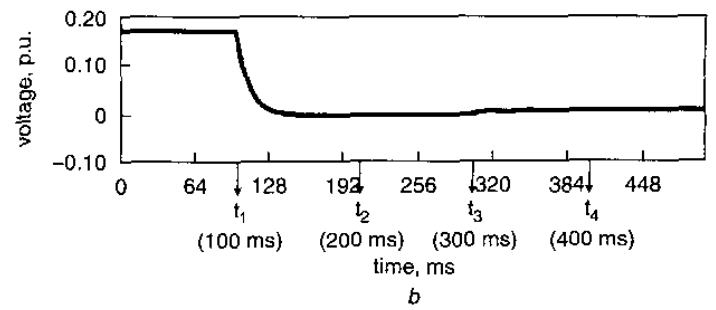

Fig. 9 System dynamic responses to a permanent fault with UPFC compensation but without PSSC modification

a Line current

$b$ Series injection voltage
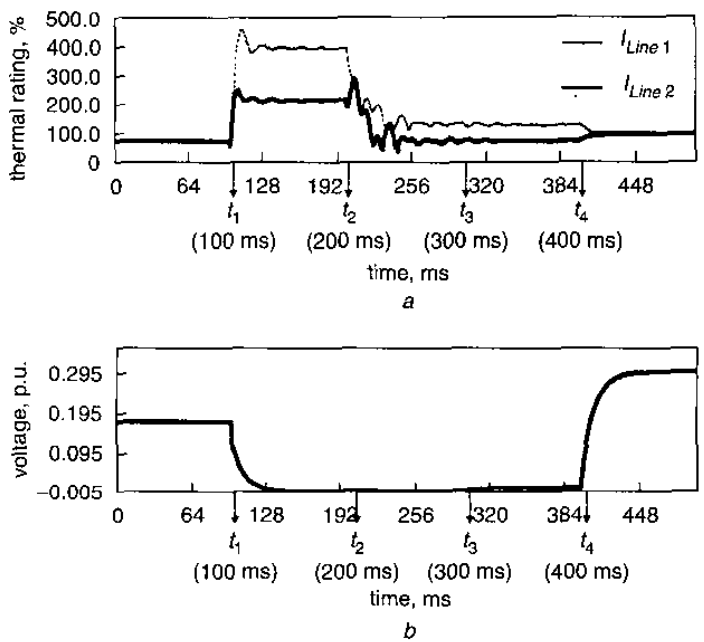

Fig. 10 System dynamic responses to a permanent fault with UPFC compensation and PSSC modification

$a$ Line current

$b$ Series injection voltage

$\left.I_{\text {Line2 }}\right)$ and the series injection voltage is reset at a value of 0.2973 p.u.

\subsection{Low-frequency electromechanical mode oscillations}

To demonstrate the effectiveness of the proposed supplementary damping controller in improving the damping for the low-frequency electromechanical mode oscillation, dynamic responses of the system subject to the same fault event as described in Section 6.1 are simulated and are depicted in Figs. 11 and 12. From the results in Figs. 11 and 12 , the following observations can be made:

(i) As evidenced by the response curves in Fig. $11 a$, the system without any compensation is oscillatory. This is as expected, because eigenvalues $-0.0566 \pm \mathrm{j} 4.9$ in the case 1 of Table 3 imply the existence of a poorly damped electromechanical mode. The response curve in Fig. $11 b$ reveals that, even when the UPFC and associated series inverter 

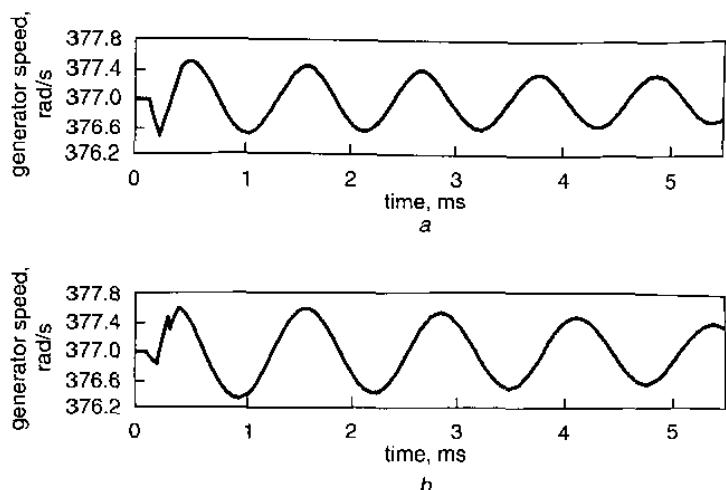

Fig. 11 System low-frequency responses under various conditions a Without UPFC compensation

$b$ With UPFC compensation but without supplementary damping controller
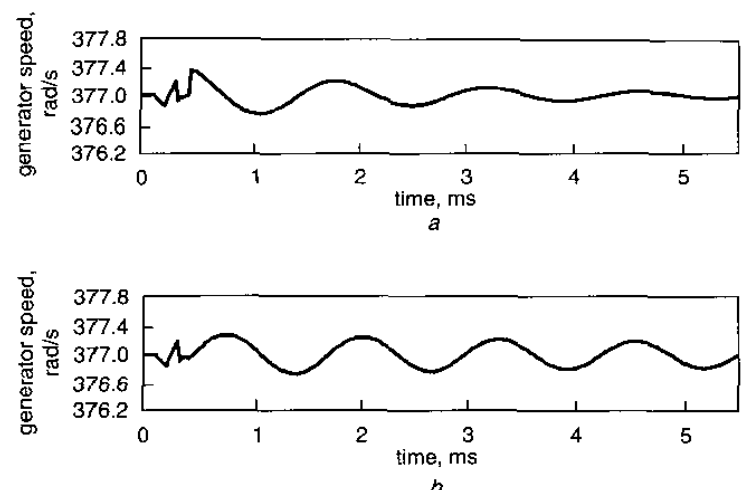

Fig. 12 System low-frequency responses under various conditions $a$ With UPFC compensation and supplementary damping controller ( $\int P_{\text {ser }} \mathrm{d} t$ as the input, $K_{P}=17.4$ and $K_{1}=1.056$ )

$b$ With UPFC compensation and supplementary damping controller (A() as the input, $K_{p}=17.4$ and $K_{1}=1.056$ )

control system and shunt inverter control system are included, no significant improvement in the damping for the electromechanical mode has been achieved by the UPFC. A comparison of the eigenvalues for this mode in case $1(-0.0566 \pm \mathrm{j} 4.9)$ and those in case $5(-0.098 \pm \mathrm{j} 4.9)$ confirms this observation from the time domain simulation results. When the supplementary damping controller is added, both the time domain simulation results in Fig. $12 a$ and the results from the eigenvalues analysis (eigenvalues are shifted from $-0.0566 \pm \mathrm{j} 4.9$ in case 1 to $-1.3 \pm \mathrm{j} 4.9$ in case 6 of Table 3) indicate significant improvements in the damping for the electromechanical mode.

(ii) In the literature, either the integral of the series active power, $\int P_{s e r} \mathrm{~d} t[5]$, or generator angular speed deviation, $\Delta \omega$ [6], has been employed as the input to the supplementary damping controller. To see which one is more effective in providing damping signals for the electromechanical mode oscillation, the dynamic response curves for systems with two different input signals and the same PI controller gains $\left(K_{P}=17.4\right.$ and $\left.K_{I}=1.056\right)$ are compared in Figs. $12 a$ and $12 b$, respectively. It is obvious from the two response curves that the integral of the series active power provides better damping effect than generator angular speed deviation.

\section{Conclusions}

A flexible UPFC control system with the power system supervisor and conditioner has been successfully applied to redistribute the power flows over the two parallel corridors and improve the low busbar voltage problem on the transmission networks of the Taiwan power system. A major feature of the present work is that the detailed dynamic gencrator model is included in the system model for the design of a UPFC controller, in order to take the effect of the actual power system on UPFC performance (especially on the low-frequency oscillations) into account.

In steady-state operation, the series power flows $P_{s e r}$ and $Q_{\text {ser }}$ and busbar voltages $\left|v_{s}\right|$ are fixed at the preset reference values $P_{s c r}^{*}, Q_{s e r}^{*}$ and $\left|v_{s}\right|^{*}$ through the action of the UPFC control system. When there is a change in system topology as a result of a permanent fault even as described in Section 6.2, the PSSC resets the reference values based on system requirements.

To improve the UPFC dynamic performance under disturbance conditions, the eigenvalues for the series inverter modes and the shunt inverter modes (with oscillation frequencies around $60 \mathrm{~Hz}$ ) are shifted to more desirable locations through the action of the power flow regulator, the shunt current regulator, the DC busbar voltage regulator and the $\mathrm{AC}$ busbar voltage regulator. $\mathrm{A}$ systematic approach based on root locus technique and pole assignment method has been presented to determine proper proportional-integral controller parameters for these regulators. Simulation results indicate that the UPFC with the designed series inverter control system and shunt inverter control system is capable of improving power system dynamic responses a under disturbance conditions. A supplementary damping controller is also designed to improve the damping for low-frequency electromechanical mode with an oscillation frequency around $0.78 \mathrm{~Hz}$. It is concluded from the simulation results that a proportionalintegral supplementary damping controller, with the integral of series active power flow $\left(\int P_{s e r} \mathrm{~d} t\right)$ as its input signal, provides good damping effect for the low-frequency clectromechanical mode.

\section{Acknowledgments}

Financial support given to this work by National Science Council of the Republic of China, under contract number NSCS89-2213-E0002-183, is appreciated by the authors of this paper.

\section{References}

1 HSU. Y.Y. SHYUE, S.W., and SU, C.C.: 'Low frequency osciliations in longitudinal power system: experience with dynamic stability of Taiwan power system, IEEE Trans. Pover Syst. 1987. 2. (1), pp. 92-100

2 LUOR, T.S., HSU, Y.Y.. WANG, S.K.. JENG, L.H.. GUO, T.Y. LIN. J.T., CHEN, Y.Y.. and HUANG, C.Y.: Application of thyristor-controlled series compensators to enhance oscillatory stability and transmission capability of a longiudinal power system". Stability and transmission capability of a longitudinal
IEEE Trans: Poner Syst. 1999, 14. (1), pp. 179-185

3 GYUGYI, L.: 'United power-flow control concept for flexible AC transmission system". IEE Proc. C. Gener. Transm. Distrih., 1992. 139 (4). pp. 323-331

4 GYUGYI. L.. SCHAUDER, C.D.. WILLIAMS. S.L.. RIETMAN, T.R., TORGERSON, D.R.. and EDRIS. A.: 'The unified power flow controller: a new approach to power transmission control'. IEEE Trans. Power Deliv., 1995. 10. (2). pp. 1085-1097

5 GYUGYI. L.: 'Dynamic compensation of AC transmission lines by solid-state synchronous voltage sources', IEEE Troms. Power Delit: 1994. 9. (2). pp. 904-911

6 SCHAUDER, C.D., GYUGYI, L., LUND, M.R., HAMAI. D.M RIETMAN, T.R.. TORGERSON, D.R, and EDRIS, A.: 'Opcration of the unified powar flow controller (UPFC) under practicit constraints'. IFEE Trans. Power Deliv. 1998, 13. (2). pp. 630-639 
7 RENZ. B.A., KERI, A., MEHRABAN, A.S., SCHAUDER. C.D., STACEY, E., KOVALSKY. L., GYUGYI, L., and EDRIS, A -AEP unified power flow controller performance. IEEE Trans. Powe Deliv, 1999, 14. (4). pp. 1374-138

8 NABAVI-NIAKI, A., and IRAVANI, M.R.: 'Steady-state and dynamic models of unified power flow controller (UPFC) for power system studies', IEEE Trans. Power Syst., [996, 11, (4) power system

9 PAPIC, I., ZUNKO, P., POVH, D., and WEINHOLD, M.: 'Basic control of the unified power flow controller', IEEE Trans. Power Syst. 1997, 12. (4), pp. 1734-1739

10 PADIYAR, K.R., and KULKARNI, A.M.: 'Control design and simulation of unified power flow controller, IEEE Trans Power Delit), 1998, 13, (4), pp. 1348-1354
11 MORIOKA. Y., KATO, M. MISHIMA, Y.. and NAKACHI, Y.: Implementation of unified power how controller and verification for transmission capability Improvement'. IEEE Trans. Power Syst., 1999. 14. (2), pp. $575-581$

12 SCHAUDER. C.D. and MEHTA. H.: "Vector analysis and control of advanced static VAR compensators, IEE Proc. C, Gener. Transm. Distrib $1993,140,(4), \mathrm{pp} .299-306$. Distrib., $193,(40,(4), p p$. $299-306$

3 ANDERSON, P.M., and FUD, A.A.: 'Power system control and stability, (IEEE Press, New York, 1994)

14 'IEEE recommended practice for excitation system models for power system stability studies.' IEEE Standard 4215,1992

15 HSU, Y.Y.: "Application of series compensation and stabilizers techniques to improve the dynamic characteristics of Tiliwan power system'. Research Report of Taiwan Power Company, 1997 